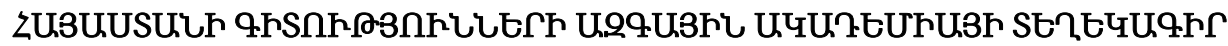 ИЗВЕСТИЯ НАЦИОНАЛЬНОЙ АКАДЕМИИ НАУК АРМЕНИИ
}

\author{
Uthuuipluw \\ 69, №2, 2016 \\ УДК 539.3

\section{ON A STRESS STATE OF ORTHOTROPIC PLANE WITH ABSOLUTELY RIGID INCLUSION}

Механика

Hakobyan V., Dashtoyan L.

\begin{abstract}
Ключевые слова: ортотропная плоскость, Кулоновское трение, абсолютно жёсткое включение, смешанная задача

Key words: orthotropic plane, Coulomb friction, absolutely rigid, mixed boundary value problem

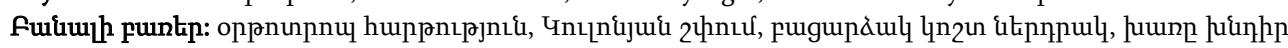

Drawing on the discontinuous solutions of the elasticity theory for orthotropic plane, the study purports to offer exact solutions to mixed boundary value problems for orthotropic plane with absolutely rigid thin inclusion on one of the major directions, when one edge of it is wholly coupled with plane and the other side is in contact with plane under the condition of Coulomb friction.
\end{abstract}

\section{Акопян В.Н., Даштоян Л.Л.}

О напряжённом состоянии ортотропной плоскости с абсолютно жёстким включением

В настоящей работе, на основе разрывных решений теории упругости для ортотропной плоскости, построено точное решение смешанной задачи для ортотропной плоскости, которая на одном из главных направлений содержит абсолютно жёсткое тонкое включение, одна из длинных сторон которого полностью сцеплена с плоскостью, а другая сторона контактирует с ней в условиях сухого трения.

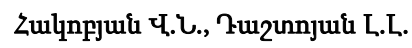

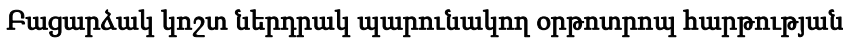

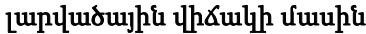

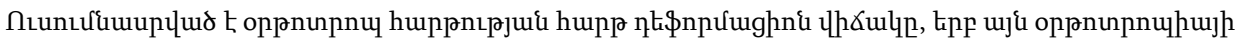

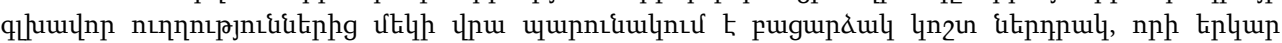

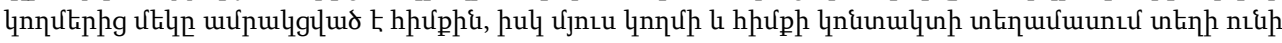

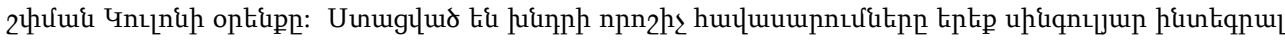

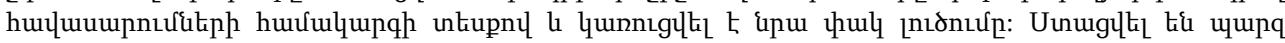

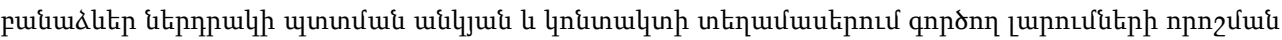

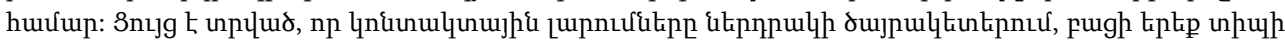

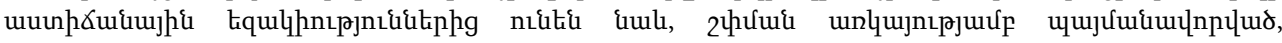

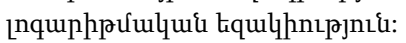

\section{Introduction}

A large number of research papers focus on the assessment of stress characteristics of elastic papers are devoted to study stress state of elastic massive bodies with thin acute-angled absolutely rigid inclusions within different models of contact of matrix with inclusion. The problems outlined above largely differ both depending on the model of contact of inclusion with matrix and elastic characteristics in case of compound bodies in boundary region could have logarithmic and some types of power singularities. Among these researches are papers [1-5], closest to the stated problem in present paper, as well as papers, given in [1]. In 
mentioned papers the exact solutions for some problems on stress state of homogeneous and compound elastic planes and space with thin acute-angled rigid inclusions, one edge of which is rigidly coupled and the other is in smooth contact with matrix is built. However, the case where one of the edges is rigidly coupled with matrix and the other is in contact with it by Coulomb friction, as the analysis suggests, is addressed for the first time.

1. The statement of problem and governing equations. Let the orthotropic elastic plane in Cartesian coordinate system $O x y$, the directions of axes of which coincide with major directions of orthotropy of planes' material, contain the absolutely rigid thin inclusion with length $2 a$, filled the interval $(-a, a)$ on line $y=0$. One of the long edges of inclusion is wholly coupled with plane and the other is in contact under conditions of Coulomb friction. It is assumed that the plane be deformed under action of moment $M_{0}$, normal and horizontal concentrated loads $P_{0}$ and $T_{0}$, applied in midpoint $x=a$ of inclusion (Fig.1). These loads do not lead to detachment the inclusion from matrix.

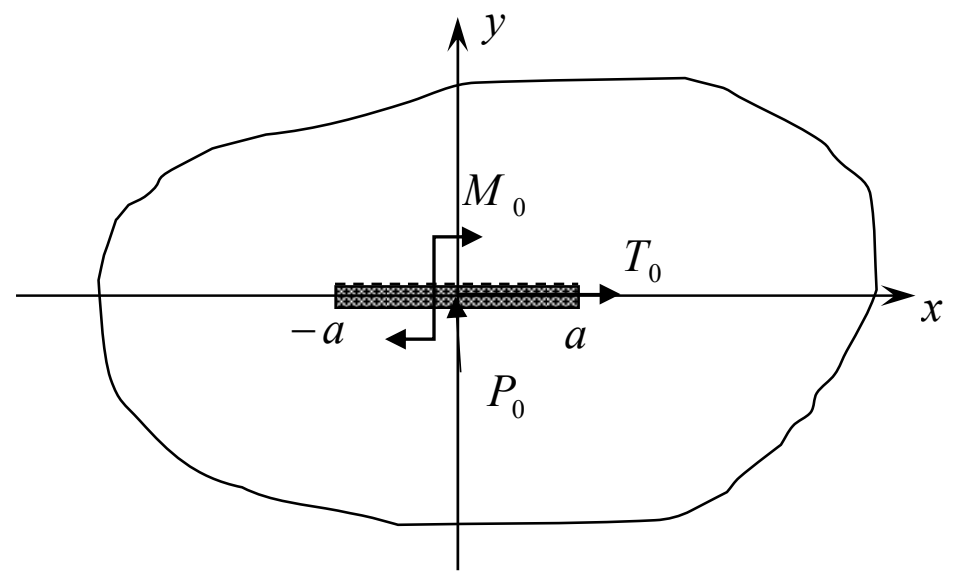

Fig.1

Problem is to determine the angle of rotation of inclusion and contact stresses, acting in regions of contacts of inclusion with matrix in explicit form, as well as to reveal the character of their changes depending on elastic characteristics of planes' material.

The stated problem can be mathematically represented as a following boundary value problem:

$\left\{\begin{array}{l}\sigma_{y}^{(+)}(x,+0)=\sigma_{y}^{(-)}(x,-0) \\ \tau_{x y}^{(+)}(x,+0)=\tau_{x y}^{(-)}(x,-0) \\ U_{+}(x,+0)=U_{-}(x,-0) \\ V_{+}(x,+0)=V_{-}(x,-0)\end{array}(|x|>a) ;\right.$ 


$$
\left\{\begin{array}{l}
U_{-}(x,-0)=\delta \\
V_{+}(x,+0)=V_{-}(x,-0)=\gamma x+\gamma_{0}(|x|<a), \\
\tau_{x y}^{(+)}(x,+0)=k \sigma_{y}^{(+)}(x,+0)
\end{array}\right.
$$

$U_{ \pm}(x, y)$ and $V_{ \pm}(x, y)$ are horizontal and normal components of displacements of points of corresponding semi-planes, each of which is satisfying Lame equations for orthotropic body in domain and is related with components of stress tensor $\sigma_{y}^{( \pm)}(x, y), \tau_{x y}^{( \pm)}(x, y)$ by well-known formulas [6]. $\gamma, \gamma_{0}$ and $\delta$ are constants, determining the angle of rotation and rigid displacements of inclusion.

In order to solve the stated problem (1) we use the discontinuous solutions for orthotropic plane, obtained in [1]:

$$
\begin{aligned}
& \frac{d U_{ \pm}(x, 0)}{d x}=-\frac{a_{1}}{\pi} \int_{L} \frac{V^{\prime}(s)}{s-x} d s-\frac{b_{1}}{\pi} \int_{L} \frac{\tau(s)}{s-x} d s \pm \frac{1}{2} U^{\prime}(x) ; \\
& \frac{d V_{ \pm}(x, 0)}{d x}=\frac{a_{2}}{\pi} \int_{L} \frac{U^{\prime}(s)}{s-x} d s-\frac{b_{2}}{\pi} \int_{L} \frac{\sigma(s)}{s-x} d s \pm \frac{1}{2} V^{\prime}(x) ; \quad(-\infty<x<\infty) \\
& \sigma_{y}^{( \pm)}(x, 0)=\frac{c_{1}}{\pi} \int_{L} \frac{V^{\prime}(s)}{s-x} d s-\frac{a_{1}}{\pi} \int_{L} \frac{\tau(s)}{s-x} d s \pm \frac{1}{2} \sigma(x) ; \\
& \tau_{x y}^{( \pm)}(x,+0)=\frac{c_{2}}{\pi} \int_{L} \frac{U^{\prime}(s)}{s-x} d s+\frac{a_{2}}{\pi} \int_{L} \frac{\sigma(s)}{s-x} d s \pm \frac{1}{2} \tau(x)
\end{aligned}
$$

$\sigma(x), \tau(x), V^{\prime}(x)$ and $U^{\prime}(x)$ be jumping functions of normal and horizontal components of stresses and displacements correspondingly

$$
\begin{aligned}
& a_{1}=\frac{\left(a_{12}-\sqrt{a_{11} a_{22}}\right)}{2 \sqrt{a_{11} a_{22}}\left(\mu_{1}+\mu_{2}\right)} ; \quad a_{2}=\sqrt{\frac{a_{11}}{a_{22}}} a_{1} ; \quad b_{1}=\frac{\left(1+\sqrt{a_{11} a_{22}}\right)}{2 \mu_{12} \sqrt{a_{11} a_{22}}\left(\mu_{1}+\mu_{2}\right)} ; \\
& b_{2}=\sqrt{\frac{a_{11}}{a_{22}} b_{1}} ; \quad c_{1}=\frac{\mu_{12}\left(a_{11} a_{22}-a_{12}^{2}\right)}{2 \sqrt{a_{11} a_{22}}\left(\mu_{1}+\mu_{2}\right)} ; \quad c_{2}=\sqrt{\frac{a_{11}}{a_{22}}} c_{1} .
\end{aligned}
$$

$a_{i j}=c_{i j} / c_{33} ; \mu_{12}=c_{33}\left(c_{i j}(i, j=1,2)-\right.$ (Cauchy tensor components).

Using relations (1.2) and satisfying the conditions (1.1b) on inclusion, previously differentiating the conditions for displacements by variable $x$ and taking into account that the difference between normal displacements of points for both sides of inclusion are the same, i.e. $V(x)=0$ we come to the following system of singular integral equations to determine the unknown jumping functions: 


$$
\left\{\begin{array}{l}
U^{\prime}(x)+\frac{2 b_{1}}{\pi} \int_{-a}^{a} \frac{\tau(\xi)}{\xi-x} d \xi=0 \\
\frac{a_{2}}{\pi} \int_{-a}^{a} \frac{U^{\prime}(\xi)}{\xi-x} d \xi-\frac{b_{2}}{\pi} \int_{-a}^{a} \frac{\sigma(\xi)}{\xi-x} d \xi=\gamma \\
\tau(x)-k \sigma(x)+\frac{2 c_{2}}{\pi} \int_{-a}^{a} \frac{U^{\prime}(\xi)}{\xi-x} d \xi+\frac{2 a_{2}}{\pi} \int_{-a}^{a} \frac{\sigma(\xi)}{\xi-x} d \xi+\frac{2 k a_{1}}{\pi} \int_{-a}^{a} \frac{\tau(\xi)}{\xi-x} d \xi=0 .
\end{array}\right.
$$

The system of equations (1.3) should be considered with conditions of equilibrium of inclusion and the equality to zero of displacements at the end-points of inclusion, i.e. with conditions

$$
\begin{aligned}
& \int_{-a}^{a} \sigma(x) d x=P_{0} ; \quad \int_{-a}^{a} \tau(x) d x=T_{0} \\
& \int_{-a}^{a} x \sigma(x) d x=M_{0} ; \int_{-a}^{a} U^{\prime}(x) d x=0 .
\end{aligned}
$$

Thus the solution of stated problem is reduced to the solution of system of singular integral equations (1.3) under conditions (1.4).

2. Solution of governing equations. The closed solution of system (1.3) should be built under conditions (1.4). In this order, from second equation (1.3), using the first and last conditions (1.4), we express function $U^{\prime}(x)$ by function $\sigma(x)$. We get

$$
U^{\prime}(x)=\frac{b_{2}}{a_{2}} \sigma(x)+\frac{\pi \gamma x-b_{2} P_{0}}{\pi a_{2} \sqrt{a^{2}-x^{2}}}
$$

Substituting the values for $U^{\prime}(x)$ from (2.1) into the first and last equations (1.3), after some transformations, the following system is obtained:

$$
\left\{\begin{array}{l}
\sigma(x)+\frac{a_{1}^{*}}{\pi} \int_{-a}^{a} \frac{\tau(\xi) d \xi}{\xi-x}=f_{1}(x) \\
\tau(x)+\frac{a_{2}^{*}}{\pi} \int_{-a}^{a} \frac{\sigma(\xi) d \xi}{\xi-x}+\frac{k b_{1}^{*}}{\pi} \int_{-a}^{a} \frac{\tau(\xi) d \xi}{\xi-x}=f_{2}(x),
\end{array}\right.
$$

Here

$$
\begin{aligned}
& f_{1}(x)=-\frac{\pi \gamma x-b_{2} P_{0}}{\pi a_{2} \sqrt{a^{2}-x^{2}}} ; f_{2}(x)=-2 \gamma c_{2}+k f_{1}(x) ; a_{1}^{*}=2 a_{2} b_{1} / b_{2} ; \\
& a_{2}^{*}=2\left(c_{2} b_{2}+a_{2}^{2}\right) / a_{2} ; b_{1}^{*}=2\left(a_{2} b_{1}+a_{1} b_{2}\right) / b_{2} .
\end{aligned}
$$

Let the functions $\varphi_{j}(x)$ be 
$\varphi_{j}(x)=\sigma(x)+\lambda_{j} \tau(x) \quad(\mathrm{j}=1,2)$,

$\lambda_{j} \quad(\mathrm{j}=1,2)$ be the solutions of equation $\lambda^{2} a_{2}^{*}-k b_{1}^{*} \lambda-a_{1}^{*}=0$. The system of equations

(2.2) will be represented as two independent singular integral equations of second kind:

$\varphi_{j}(x)+\frac{q_{j}}{\pi} \int_{-a}^{a} \frac{\varphi_{j}(\xi) d \xi}{\xi-x}=g_{j}(x) \quad(j=1,2)$

Here

$g_{j}(x)=-\gamma A_{0}^{(j)}-\frac{\gamma A_{1}^{(j)} x-A_{2}^{(j)}}{\sqrt{a^{2}-x^{2}}}$

$A_{0}^{(j)}=2 c_{2} \lambda_{j} ; A_{1}^{(j)}=\frac{1+k \lambda_{j}}{b_{2}} ; A_{2}^{(j)}=\frac{\left(1+k \lambda_{j}\right) P_{0}}{\pi} ;$

$q_{j}=a_{2}^{*} \lambda_{j}=\left(k b_{1}^{*}+(-1)^{j+1} \sqrt{\left(k b_{1}^{*}\right)^{2}+4 a_{1}^{*} a_{2}^{*}}\right) / 2$.

In this case, the first three conditions (1.4) are written in the following form using functions $\varphi_{j}(x)$

$$
\begin{gathered}
\int_{-a}^{a} \varphi_{j}(x) d x=P_{0}^{(j)} ; \int_{-a}^{a}\left[\lambda_{2} \varphi_{1}(x)-\lambda_{1} \varphi_{2}(x)\right] x d x=M_{0} ; \\
\left(P_{0}^{(j)}=P_{0}+\lambda_{j} T_{0} ; j=1,2\right) .
\end{gathered}
$$

The solutions of the system of singular integral equations (2.3), satisfying the first of conditions (2.4) are given by the formulas $[1,6]$ :

$\varphi_{j}(x)=\frac{1}{1+q^{2}}\left[g_{j}(x)-\frac{q_{j} X_{j}^{+}(x)}{\pi} \int_{-a}^{a} \frac{g_{j}(s)}{X_{j}^{+}(s)(s-x)} d s\right]-\frac{P_{0}^{(j)} \sin \pi \gamma_{j}}{\pi \sqrt{G_{j}}} X_{j}^{+}(x)$

Here $X_{j}^{+}(x)=-\sqrt{G_{j}} / \omega_{j}(x)$ be the values of analytic in whole plane cutting along interval $(-a, a)$ functions $X_{j}(z)=(z+a)^{-\gamma_{j}}(z-a)^{\gamma_{j}-1}(j=1,2)$ on the upper bank of slit, where

$$
\begin{aligned}
& \omega_{j}(x)=(a+x)^{\gamma_{j}}(a-x)^{1-\gamma_{j}} ; \\
& \gamma_{j}=\frac{1}{2 \pi i} \ln \left|G_{j}\right|+\frac{\vartheta_{j}}{2 \pi} ; 0<\vartheta_{j}=\arg G_{j}<2 \pi ; \quad G_{j}=\frac{1-i q_{j}}{1+i q_{j}} .
\end{aligned}
$$

Taking into account that the numbers $\lambda_{j}(j=1,2)$ are real, it is not difficult to state that $\left|G_{j}\right|=1$. Therefore, the exponents $\gamma_{j}=\vartheta_{j} / 2 \pi,(j=1,2)$ are real.

Then, substituting the values of functions $g_{j}(x)$ in (2.5) and taking into account the values of integrals $[6,7]$ 


$$
\begin{aligned}
& \int_{-a}^{a} \frac{\omega_{j}(s) d s}{s-x}=-\frac{\pi}{\sin \left(\pi \gamma_{j}\right)}\left[\cos \left(\pi \gamma_{j}\right) \omega_{j}(s)+x+a\left(2 \gamma_{j}-1\right)\right] \quad(|x|<a) \\
& \int_{-a}^{a} \frac{\omega_{j}(s) d s}{\sqrt{a^{2}-s^{2}}(s-x)}=\frac{\pi}{\cos \left(\pi \gamma_{j}\right)}\left[\frac{\sin \left(\pi \gamma_{j}\right) \omega_{j}(x)}{\sqrt{a^{2}-x^{2}}}-1\right] \quad(|x|<a), \\
& \int_{-a}^{a} \frac{s \omega_{j}(s) d s}{\sqrt{a^{2}-s^{2}}(s-x)}=-\frac{a\left(2 \gamma_{j}-1\right)}{\cos \left(\pi \gamma_{j}\right)}+\frac{\pi x}{\cos \left(\pi \gamma_{j}\right)}\left[\frac{\sin \left(\pi \gamma_{j}\right) \omega_{j}(x)}{\sqrt{a^{2}-x^{2}}}-1\right] \quad(|x|<a)
\end{aligned}
$$

for functions $\varphi_{j}(x)$ the following expressions are obtained:

$\varphi_{j}(x)=B_{0}^{(j)}+\frac{B_{1}^{(j)}(x)}{\sqrt{a^{2}-x^{2}}}+\frac{B_{2}^{(j)}(x)}{\omega_{j}(x)} ; \quad(|x|<a ; j=1,2)$

Here we use the following notation:

$$
\begin{aligned}
& B_{0}^{(j)}=-\gamma A_{0}^{(j)} \frac{1+q_{j} \operatorname{ctg}\left(\pi \gamma_{j}\right)}{1+q_{j}^{2}} ; B_{1}^{(j)}=e_{1}^{(j)} x+e_{0}^{(j)} ; B_{2}^{(j)}=d_{1}^{(j)} x+d_{0}^{(j)} ; \\
& e_{1}^{(j)}=-\gamma e_{1 j}^{*} ; e_{0}^{(j)}=\frac{A_{2}^{(j)}\left(1-q_{j} \operatorname{tg}\left(\pi \gamma_{j}\right)\right)}{1+q_{j}^{2}} ; d_{1}^{(j)}=-\gamma d_{1 j}^{*} ; d_{0}^{(j)}=-\gamma d_{0 j}^{*}+\mathrm{m}_{0 j}^{*} ; \\
& d_{0 j}^{*}=\frac{a_{0}^{(j)} q_{j}}{1+q_{j}^{2}}\left[\frac{A_{0}^{(j)}}{\sin \left(\pi \gamma_{j}\right)}+\frac{A_{1}^{(j)}}{\cos \left(\pi \gamma_{j}\right)}\right] ; \mathrm{m}_{0 j}^{*}=\frac{P_{0}^{(j)} \sin \left(\pi \gamma_{j}\right)}{\pi}+\frac{q_{j} A_{2}^{(j)}}{\left(1+q_{j}^{2}\right) \cos \left(\pi \gamma_{j}\right)} ; \\
& e_{1 j}^{*}=\frac{A_{1}^{(j)}\left(1-q_{j} \operatorname{tg}\left(\pi \gamma_{j}\right)\right)}{1+q_{j}^{2}} ; d_{1 j}^{*}=\frac{q_{j}}{1+q_{j}^{2}}\left[\frac{A_{0}^{(j)}}{\sin \left(\pi \gamma_{j}\right)}+\frac{A_{1}^{(j)}}{\cos \left(\pi \gamma_{j}\right)}\right] ; a_{0}^{(j)}=a\left(2 \gamma_{j}-1\right) .
\end{aligned}
$$

Now we can determine the angle of rotation $\gamma$ of inclusion. In this order we use the second relation from (2.4). Substituting the values for functions $\varphi_{j}(x)(j=1,2)$ from (2.6) in this relation, and calculating obtained integrals, after some simplifications, we find

$$
\gamma=\frac{M+\lambda_{1} D_{2}-\lambda_{2} D_{1}}{\lambda_{1} E_{2}-\lambda_{2} E_{1}}
$$

here

$$
D_{j}=-\frac{\pi a_{0}^{(j)}}{\sin \left(\pi \gamma_{j}\right)} m_{0 j}^{*}
$$




$$
E_{j}=\frac{\pi a^{2}}{2} e_{1 j}^{*}+\frac{\pi a^{2}\left(1-2 \gamma_{j}\left(1-\gamma_{j}\right)\right)}{\sin \left(\pi \gamma_{j}\right)} d_{1 j}^{*}-\frac{\pi a_{0}^{(j)}}{\sin \left(\pi \gamma_{j}\right)} d_{0 j}^{*}(j=1,2)
$$

Now we can determine normal and shear stresses, acting on long edges of inclusion. Using formulas

$$
\sigma(x)=\frac{\lambda_{2} \varphi_{1}(x)-\lambda_{1} \varphi_{2}(x)}{\lambda_{2}-\lambda_{1}} ; \quad \tau(x)=\frac{\varphi_{1}(x)-\varphi_{2}(x)}{\lambda_{1}-\lambda_{2}}
$$

first we determine the jump-functions of stresses. Substituting the expression for $\varphi_{j}(x)$ from (2.6), we get

$$
\begin{aligned}
& \sigma(x)=\frac{1}{\lambda_{2}-\lambda_{1}}\left\{\lambda_{2} B_{0}^{(1)}-\lambda_{1} B_{0}^{(2)}+\frac{\lambda_{2} B_{1}^{(1)}(x)-\lambda_{1} B_{1}^{(2)}(x)}{\sqrt{a^{2}-x^{2}}}+\frac{\lambda_{2} B_{2}^{(1)}(x)}{\omega_{1}(x)}-\frac{\lambda_{1} B_{2}^{(2)}(x)}{\omega_{1}(x)}\right\} ; \\
& \tau(x)=\frac{1}{\lambda_{1}-\lambda_{2}}\left\{B_{0}^{(1)}-B_{0}^{(2)}+\frac{B_{1}^{(1)}(x)-B_{1}^{(2)}(x)}{\sqrt{a^{2}-x^{2}}}+\frac{B_{2}^{(1)}(x)}{\omega_{1}(x)}-\frac{B_{2}^{(2)}(x)}{\omega_{1}(x)}\right\} .
\end{aligned}
$$

Using obtained relations and two last formulas (1.2) the following formulas is obtained for normal contact stresses:

$$
\sigma_{y}^{ \pm}(x, \pm 0)=A_{ \pm}+\mathrm{B} \ln \left|\frac{a-x}{a+x}\right| \pm \frac{K_{I}(x)}{\sqrt{a^{2}-x^{2}}}+\frac{K_{I}^{(1)}(x)}{\omega_{1}(x)}+\frac{K_{I}^{(2)}(x)}{\omega_{2}(x)} .
$$

In this case

$$
\begin{aligned}
& A_{ \pm}=-\frac{1}{\left(\lambda_{2}-\lambda_{1}\right)}\left[a_{1}\left(\frac{d_{1}^{(2)}}{\sin \left(\pi \gamma_{2}\right)}-\frac{d_{1}^{(1)}}{\sin \left(\pi \gamma_{1}\right)}\right) \mp \frac{\left(\lambda_{2} B_{0}^{(1)}-\lambda_{1} B_{0}^{(2)}\right)}{\pi}+a_{1}\left(e_{1}^{(1)}-e_{1}^{(2)}\right)\right] ; \\
& B=\frac{a_{1}\left(B_{0}^{(1)}-B_{0}^{(2)}\right)}{\pi\left(\lambda_{2}-\lambda_{1}\right)} ; \mathrm{K}_{I}(x)= \pm \frac{\left(\lambda_{2} B_{1}^{(1)}(x)-\lambda_{1} B_{1}^{(2)}(x)\right)}{2\left(\lambda_{2}-\lambda_{1}\right)} ; \\
& \mathrm{K}_{I}^{(1)}(x)=\frac{2 a_{1} \operatorname{ctg}\left(\pi \gamma_{1}\right) \pm \lambda_{2}}{2\left(\lambda_{2}-\lambda_{1}\right)} B_{2}^{(1)}(x) ; \mathrm{K}_{I}^{(2)}(x)=-\frac{2 a_{1} \operatorname{ctg}\left(\pi \gamma_{2}\right) \pm \lambda_{1}}{2\left(\lambda_{2}-\lambda_{1}\right)} B_{2}^{(2)}(x) .
\end{aligned}
$$

For shear contact stresses, acting in junction region of inclusion with matrix, we have $\tau_{x y}^{-}(x,-0)=A_{*}+\mathrm{B}_{*} \ln \left|\frac{a-x}{a+x}\right|+\frac{K_{I I}(x)}{\sqrt{a^{2}-x^{2}}}+\frac{K_{I I}^{(1)}(x)}{\omega_{1}(x)}+\frac{K_{I I}^{(2)}(x)}{\omega_{2}(x)}$, here 


$$
\begin{aligned}
& A_{*}=\gamma c_{2}+\frac{1}{2\left(\lambda_{2}-\lambda_{1}\right)}\left[B_{0}^{(1)}-B_{0}^{(2)}-a_{2}^{*}\left(\lambda_{2} e_{1}^{(1)}-\lambda_{1} e_{1}^{(2)}\right)-a_{2}^{*}\left(\frac{\lambda_{2} d_{1}^{(1)}}{\sin \left(\pi \gamma_{1}\right)}-\frac{\lambda_{1} d_{1}^{(2)}}{\sin \left(\pi \gamma_{2}\right)}\right)\right] \\
& B_{*}=\frac{a_{2}^{*}\left(\lambda_{2} B_{0}^{(1)}-\lambda_{1} B_{0}^{(2)}\right)}{2 \pi\left(\lambda_{2}-\lambda_{1}\right)} ; K_{I I}(x)=\frac{B_{1}^{(1)}(x)-B_{1}^{(2)}(x)}{2\left(\lambda_{2}-\lambda_{1}\right)} ; \\
& \mathrm{K}_{I I}^{(1)}(x)=\frac{\lambda_{2} a_{2}^{*} \operatorname{ctg}\left(\pi \gamma_{1}\right)+1}{2\left(\lambda_{2}-\lambda_{1}\right)} B_{2}^{(1)}(x) ; \mathrm{K}_{I I}^{(2)}(x)=-\frac{\lambda_{1} a_{2}^{*} \operatorname{ctg}\left(\pi \gamma_{2}\right)+1}{2\left(\lambda_{2}-\lambda_{1}\right)} B_{2}^{(2)}(x) .
\end{aligned}
$$

As we can see from obtained formulas, the contact stresses at the contact stresses at the end-points of inclusion, besides three types of exponential singularities, have logarithmic singularity, which is due to the rotation of inclusion, arising as a result of asymmetrical loads. It is easy to check that in case of smooth contact $(k=0)$ when torsion moment $M_{0}$ and horizontal load $T_{0}$ are absent, we get $\gamma=0$ using formula (2.7). In consequence of this the coefficients $A_{ \pm}, B, A_{*}$ and $B_{*}$ become zero and logarithmic singularity is vanished. From formulas (2.8) for stated case we get the expressions for jumps of stresses mentioned in [1]. For this special case the expressions for contact stresses are are the following:

$$
\begin{aligned}
& \sigma_{y}^{ \pm}(x, \pm 0)= \pm \frac{K_{I}}{\sqrt{a^{2}-x^{2}}}+K_{I}^{(1)}(x)[\omega(x)+\omega(-x)] ; \\
& \tau_{y}^{-}(x,-0)=K_{I I}[\omega(x)+\omega(-x)] .
\end{aligned}
$$

Here

$$
\begin{gathered}
K_{\mathrm{I}}=\frac{P_{0}}{\pi\left(1+q^{2}\right)}\left[1+q \operatorname{tg} \pi \gamma_{1}\right] ; \quad K_{\mathrm{I}}^{(1)}=\frac{P_{0}}{2 \pi}\left[\sin \pi \gamma_{1}+\frac{q}{\left(1+q^{2}\right) \cos \pi \gamma_{1}}\right] ; \\
K_{\mathrm{II}}=\frac{\left[\lambda a_{2}^{*} \operatorname{ctg}\left(\pi \gamma_{1}\right)-1\right]}{4 \lambda} K_{\mathrm{I}}^{(1)} ; \omega(x)=(a+x)^{-\gamma_{1}}(a-x)^{\gamma_{1}-1} ; \\
\left(q_{j}=(-1)^{j+1} q ; \lambda_{1}=-\lambda_{2}=\lambda=2 \sqrt{a_{1}^{*} / a_{2}^{*}} ; \gamma_{2}=1-\gamma_{1}\right) .
\end{gathered}
$$

Summary. The exact solution for problem on a stress state of orthotropic elastic plane with absolutely rigid thin inclusion on one of the major direction, when one long edge of inclusion is wholly coupled with plane and the other side is in contact with plane under conditions of Coulomb friction, is built by the method of singular integral equations.

It is shown that under asymmetrical loading of inclusion the contact stresses, acting on long edge, besides exponential singularities, have logarythmic singularity as well. In stated problem the simple expression for one of the most important mechanical characteristics, which is angle of rotation of inclusion, is obtained. 


\section{REFERENCES}

1. Акопян В.Н. Смешанные граничные задачи о взаимодействии сплошных деформируемых тел с концентраторами напряжений различных типов. Ереван: Изд. «Гитутюн» НАН РА, 2014. 322c.

2. Акопян В.Н., Саргсян А.О. О концентрации напряжений возле абсолютно жёсткого включения в составной упругой полуплоскости // Изв. НАН Армении. Механика. 2010. Т.63. №4. С.12-22.

3. Акопян В.Н. Напряжения возле абсолютно жёсткого монетообразного включения в кусочно-однородном пространстве // В сб. трудов межд. конференции: «Актуальные проблемы механики сплошной среды», посв. 95-летию со дня рожд. Акад. Н.Х.Арутюняна, Ереван-2007, с.45-51.

4. Даштоян Л.Л., Акопян Л.В. Плоско-деформированное состояние составной плоскости с периодической системой абсолютно жёстких тонких включений. //«Проблемы динамики взаимодействия деформируемых сред», сентябрь 19-23, 2011, Горис-Степанакерт, с.172-176.

5. Ильина И.И., Сильвестров В.В. Задача о тонком жёстком включении, отсоединившемся вдоль одной стороны от среды. // Изв. РАН. МТТ. 2005. №3. С.153-166.

6. Мусхелишвили Н.И. Некоторые основные задачи математической теории упругости. М.: Наука, 1966.708c.

7. Прудников А.П., Брычков Ю.А., Маричев О.И. Интегралы и ряды. М.: Наука, 1981. $738 \mathrm{c}$.

\section{Information about authors:}

Hakobyan Vahram -Doctor of Sciences, Professor, Director of the Institute of Mechanics NAS RA, phone.: (37410) 52-48-90, e-mail: vhakobyan@sci.am

Dashtoyan Lilit - Doctor of Mechanics, Scientific Secretary of the Institute of Mechanics NAS RA, phone: (37410) 52-81-89, e-mail: 1ilit_dashtoyan@mechins.sci.am

Поступила в редакцию 15.04.2016 